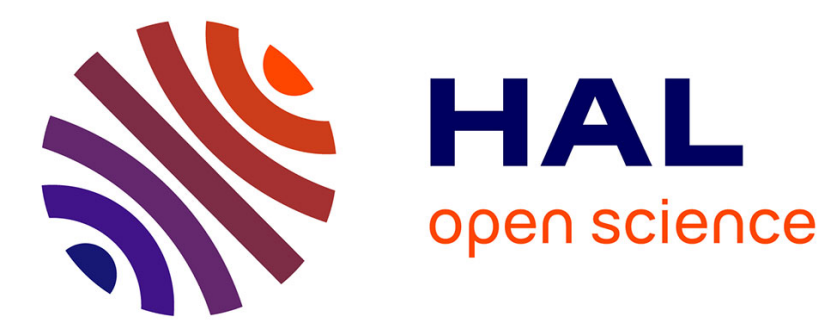

\title{
The base line problem in DLTS technique
}

G. Couturier, A. Thabti, A.S. Barrière

\section{- To cite this version:}

G. Couturier, A. Thabti, A.S. Barrière. The base line problem in DLTS technique. Revue de Physique Appliquée, 1989, 24 (2), pp.243-249. 10.1051/rphysap:01989002402024300 . jpa-00246046

\section{HAL Id: jpa-00246046 https://hal.science/jpa-00246046}

Submitted on 1 Jan 1989

HAL is a multi-disciplinary open access archive for the deposit and dissemination of scientific research documents, whether they are published or not. The documents may come from teaching and research institutions in France or abroad, or from public or private research centers.
L'archive ouverte pluridisciplinaire HAL, est destinée au dépôt et à la diffusion de documents scientifiques de niveau recherche, publiés ou non, émanant des établissements d'enseignement et de recherche français ou étrangers, des laboratoires publics ou privés. 
Classification

Physics Abstracts

71.55

\title{
The base line problem in DLTS technique
}

\author{
G. Couturier, A. Thabti and A. S. Barrière \\ LEMME, Université de Bordeaux 1, 351 Cours de la libération, 33405 Talence Cedex, France
}

(Reçu le 30 juin 1988, révisé le 20 octobre 1988, accepté le 24 octobre 1988)

\begin{abstract}
Résumé. - Ce papier décrit une méthode pour supprimer le problème posé par la ligne de base en spectroscopie DLTS utilisant une détection synchrone. La méthode a été utilisée pour caractériser les pièges profonds dans une diode Schottky GaAs. Une comparaison avec la méthode classique utilisant un capacimètre en mode différentiel est donnée. Une étude de la dépendance du signal DLTS en fonction du champ électrique dans un semiconducteur faiblement dopé est également rapportée et prouve l'efficacité de la méthode. Finalement, le dépouillement des résultats est largement discuté.
\end{abstract}

\begin{abstract}
This paper describes a solution to suppress the base line problem in DLTS spectroscopy using a lock-in amplifier. The method has been used to characterize deep levels in a GaAs Schottky diode. Comparison with the classical method based on the use of a capacitance meter in the differential mode is established. The electric field dependence of the DLTS signal in a weakly doped semiconductor is also reported and proves the efficiency of the method. Finally, the data process is discussed.
\end{abstract}

\section{Introduction.}

The DLTS technique is a very powerful technique to characterize deep levels in the bulk of the semiconductors [1] or (and) interface electronic states in MOS structures $[2,3]$. This technique was first developed by Lang in 1974 . The basic idea of the method is the rate-window concept [4] which makes use of the fact that a transient response of a current or a capacitance with a constant repetition rate at a period $T_{0}$ will give a maximum if the time constant of the phenomenon under study is close to some preselected values.

The initial experimental set up used a double - boxcar which samples the transient decay $S(t, T) \propto$ $\mathrm{e}^{-t / \tau(T)}$ of the capacitance of a Schottky diode or a $\mathrm{P}^{+} / \mathrm{N}\left(\mathrm{N}^{+} / \mathrm{P}\right)$ junction at two preselected times $t_{1}$ and $t_{2}$. The signal difference, $S\left(t_{1}, T\right)-S\left(t_{2}, T\right)$ exhibits a maximum at a temperature $T=T_{\mathrm{M}}$. It is easy to demonstrate that the time constant $\tau\left(T_{M}\right)$ of the transient decay at the $T_{\mathrm{M}}$ temperature verifies the following law: $\tau\left(T_{\mathrm{M}}\right)=\left(t_{1}-t_{2}\right) / \operatorname{Ln}\left(t_{1} / t_{2}\right)$. The boxcar technique is very simple but presents some disadvantages, in particular a poor signal to noise ratio because only two samples of the transient decay are processed.

A second technique has been developped and it uses a lock-in amplifier. In a simple phase lock-in amplifier the transient decay is now multiplied by +1 during the first half period, i.e. $T_{0} / 2$, and by -1 for the second one. By using a very short refilling pulse with a duration $t_{\mathrm{p}}$ compared to the period $T_{0}$, it can be demonstrated that the time constant $\tau\left(T_{\mathrm{M}}\right)$ at the maximum of the DLTS signal is now given by $\tau\left(T_{\mathrm{M}}\right)=0.39 T_{0}$. A plot of the $\tau\left(T_{\mathrm{M}}\right) T^{2} \propto T_{0} T_{\mathrm{M}}^{2}$ quantity as a function of the inverse of the temperature $T_{\mathrm{M}}^{-1}$ allows to determine the ionisation energy and the capture cross section of the deep level.

A lock-in preamplifier can be used either in the flat band mode (FB) or the band pass mode (BP). In the FB mode the total signal at the output of the capacitance meter is processed by the lock-in amplifier whereas in the BP mode only the first harmonic or even the second is treated. Due to the reduction of the band pass of the preamplifier the BP method has a better signal to noise ratio.

Whatever the selected mode, it is necessary to suppress the output signal of the capacitance meter while the refilling pulse with a duration $t_{\mathrm{p}}$ is applied to the structure. Indeed, during this time the capacitance of the diode under test takes a high value and would lead to a selection of a very poor sensitivity of the lock-in preamplifier. Among the different methods proposed to eliminate the response of the capacitance meter during $t_{\mathrm{p}}$, we can mention those 
suggested by Pons et al. [5]. This method is known as the «A-B » technique, the capacitance meter signal is multiplied by $+\pi / 2 \sqrt{2}$ in the $\left(T_{0} / 4, T_{0} / 2\right)$ intervall, by $-\pi / 2 \sqrt{2}$ in the $\left(3 T_{0} / 4, T_{0}\right)$ intervall and by zero elsewhere. Another solution was proposed by Tokuda et al. [6] and it uses fast analogic switches in order to deselect the lock-in amplifier during the time $t_{\mathrm{p}}$. Putting the signal at zero at the input of the lock-in amplifier during $t_{\mathrm{p}}$ leads to a non zero base line for the DLTS signal. This behaviour can be partially compensated for by using the capacitance meter in the differential mode. But, due to the temperature dependence of the depletionlayer capacitance of the Schottky diode, this method does not allow us to obtain a zero base line over the entire range of temperature. It is clear that the base line drift can be practically neglected if the duration $t_{\mathrm{p}}$ of the refilling pulse remains short compared to the period $T_{0}$. Here we propose a simple and low cost method to get an exact zero base line whatever the temperature, the pulse duration $t_{\mathrm{p}}$ and the period $T_{0}$.

\section{Instrumentation.}

Our experimental set-up is essentially built around a lock-in amplifier PAR 124 and a capacitance meter Booton $72 \mathrm{~B}$. The aim of the method is based on a sampling and holding of the capacitance signal at the period $N$, just before the application of a new refilling pulse. The lock-in amplifier input signal is now the substraction of the capacitance signal of the period $N+1$ and the sampling at the period $N$. As a consequence, if no deep level is present in the diode under study the base line of the DLTS signal is exactly zero and it is no longer sensitive to the temperature dependence of the depletion-layer capacitance of the junction. The capacitance meter can then be used with no differential capacitance.

To illustrate the method the block diagram of the experimental set up and the corresponding chronogram are shown in figure 1 and 2 respectively.

A refilling pulse of duration $t_{\mathrm{p}}$ is applied to the junction. The bias voltage $V_{1}$ and the pulse with a height $V_{1}-V_{2}$ are built with two power supplies

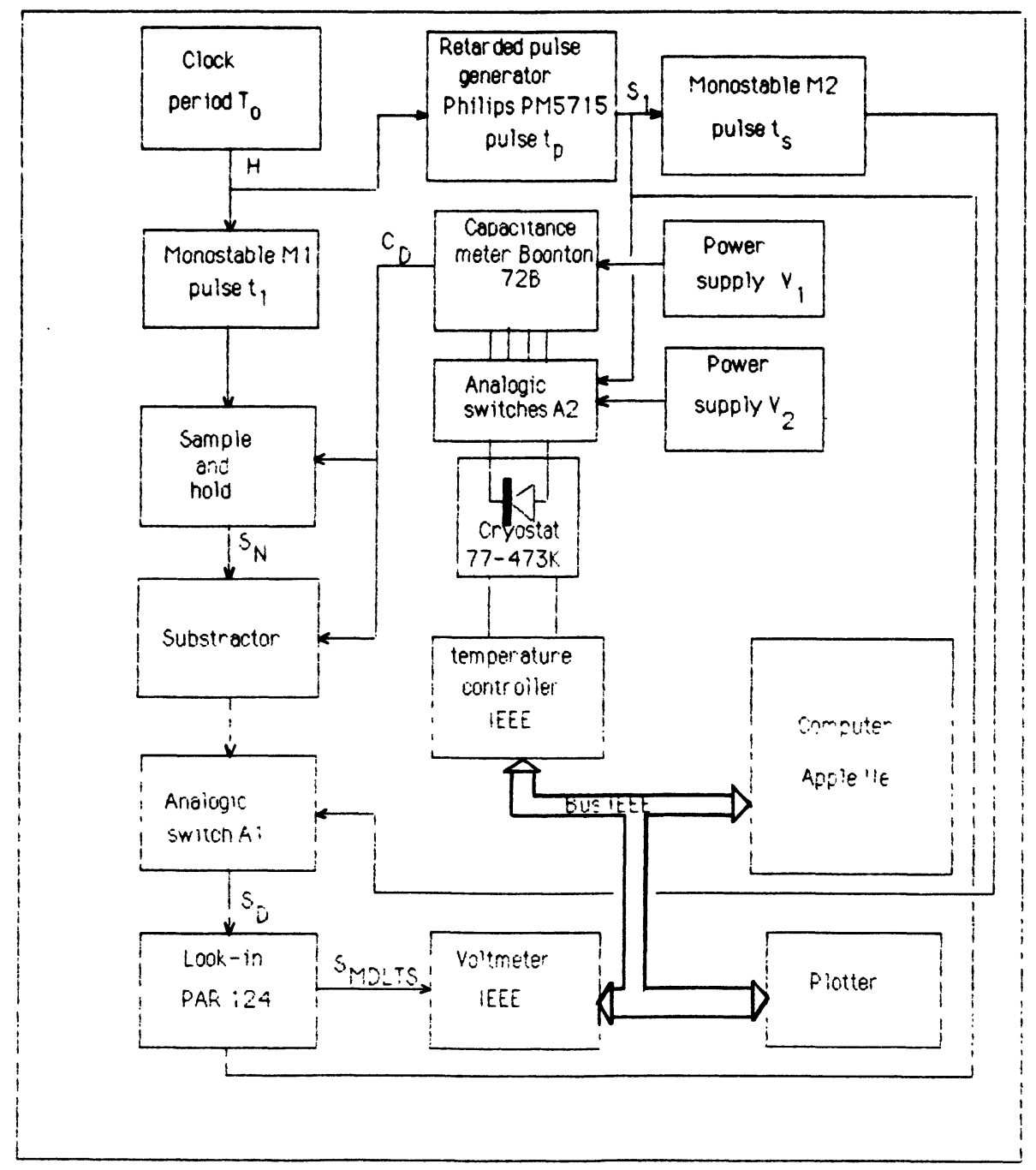

Fig. 1. - Block diagram of the system. 


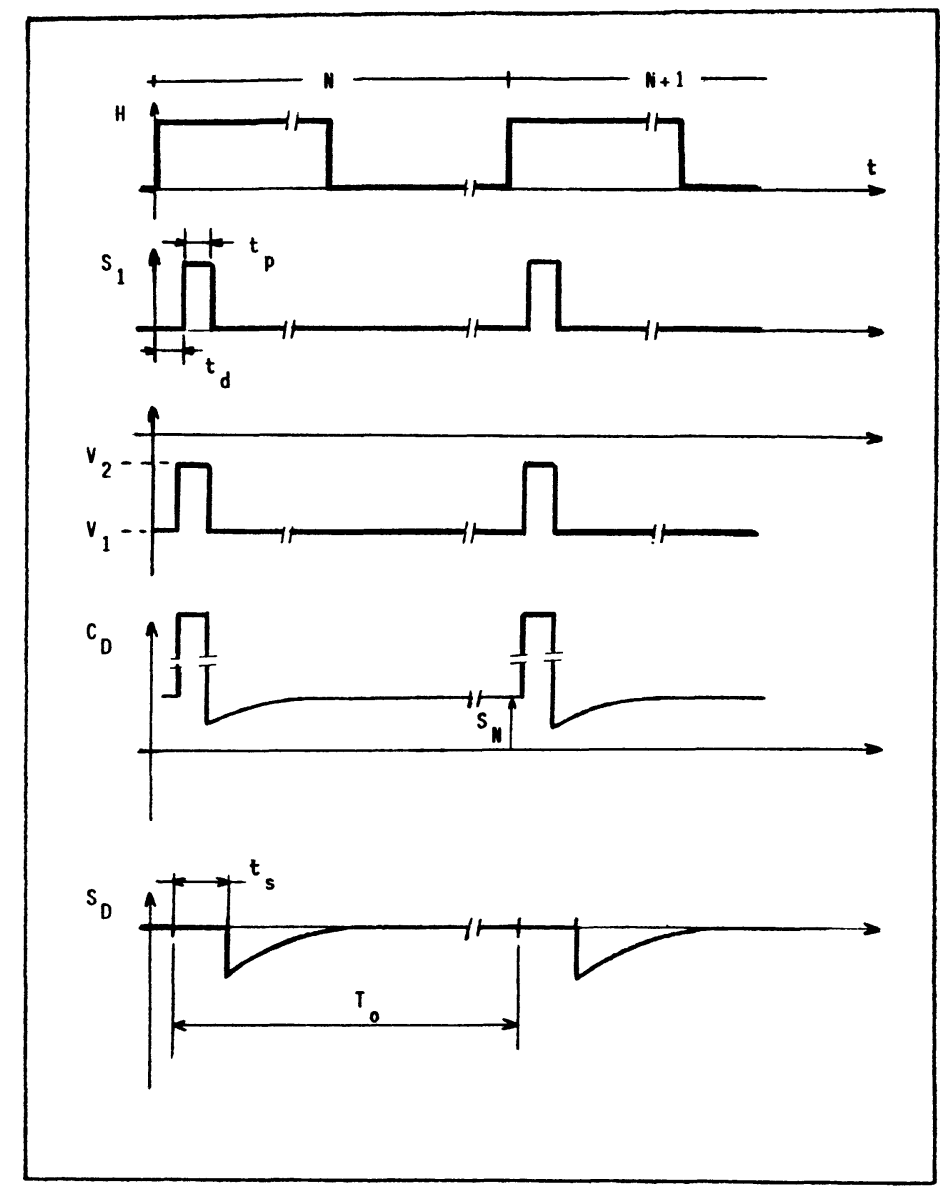

Fig. 2. - Signal chronogram, see the figure 1 for the notation.

$V_{1}$ and $V_{2}$. These are commuted by fast analogic switches (A2). This solution, suggested to us by Le Bloa et al. [7], permits the application of very short pulses to the diode $\left(t_{\mathrm{p} \min } \sim 200 \mathrm{~ns}\right)$. The refilling pulse is generated in synchronism with a TTL pulse $\left(\mathrm{S}_{1}\right)$ delivered with a delay $t_{\mathrm{d}}(\sim 150 \mu \mathrm{s})$ by a retarded pulse generator edge triggered by a clock $(\mathrm{H})$ at a period $T_{0}$. The time interval $t_{\mathrm{d}}$ is then used to sample the capacitance signal $C_{\mathrm{D}}$ at the period $N$ and the sampling value $\left(S_{N}\right)$ is held for the period $N+1$. The lock-in amplifier which is also synchronized by the pulse $S_{1}$ now receives the output capacitance meter signal of the period $N+1$ minus the voltage $S_{N}$. As mentioned previously the lock-in amplifier is disconnected while the pulse is applied to the structure. However, the reason in this case is not because the capacitance signal is high when the junction is put in less inversion. In fact, the modifications of the capacitance meter in order to apply short duration pulses to the diode leads to a zero output for the duration $t_{\mathrm{p}}$. Nevertheless, there is still a good reason to suppress the signal for a duration $t_{\mathrm{s}}$ greater than $t_{\mathrm{p}}$ in order to eliminate the time response of the capacitance meter. This is done by the analogic switch A1 in figure 1. After modification the time constant of this apparatus has been reduced to about $180 \mu$ s but the signal to noise ratio is decreased. The DLTS signal is then recorded by means of a computer via an IEEE bus. In the following, the lock-in amplifier is always used in the band pass mode, so only the first harmonic of the signal has to be considered.

\section{Data processing.}

To prove the efficiency of the method two DLTS spectra of an $\mathrm{Au} / \mathrm{GaAs}(\mathrm{n})$ Schottky diode are reported in figure 3 . The spectrum $\{a\}$ is recorded with the classical method, i.e. with the capacitance meter using the differential method and the output capacitance meter is directly connected to the lockin amplifier. The differential capacitance has been adjusted so that the DLTS signal is zero at $100 \mathrm{~K}$. The second spectrum $\{b\}$ is recorded with the method described here. In these experiments a refilling pulse of majority carriers with a duration $t_{\mathrm{p}}=1 \mathrm{~ms}$ was applied to the structure, the others parameters $t_{\mathrm{s}}$ and $T_{0}$ were respectively $2 \mathrm{~ms}$ and $30 \mathrm{~ms}$. Only three DLTS peaks are observed in the spectrum $\{a\}$ whereas four peaks $\left(E_{0} \rightarrow E_{3}\right)$ are clearly exhibited in spectrum $\{b\}$. Our intention here is not to discuss the chemical origin of the 


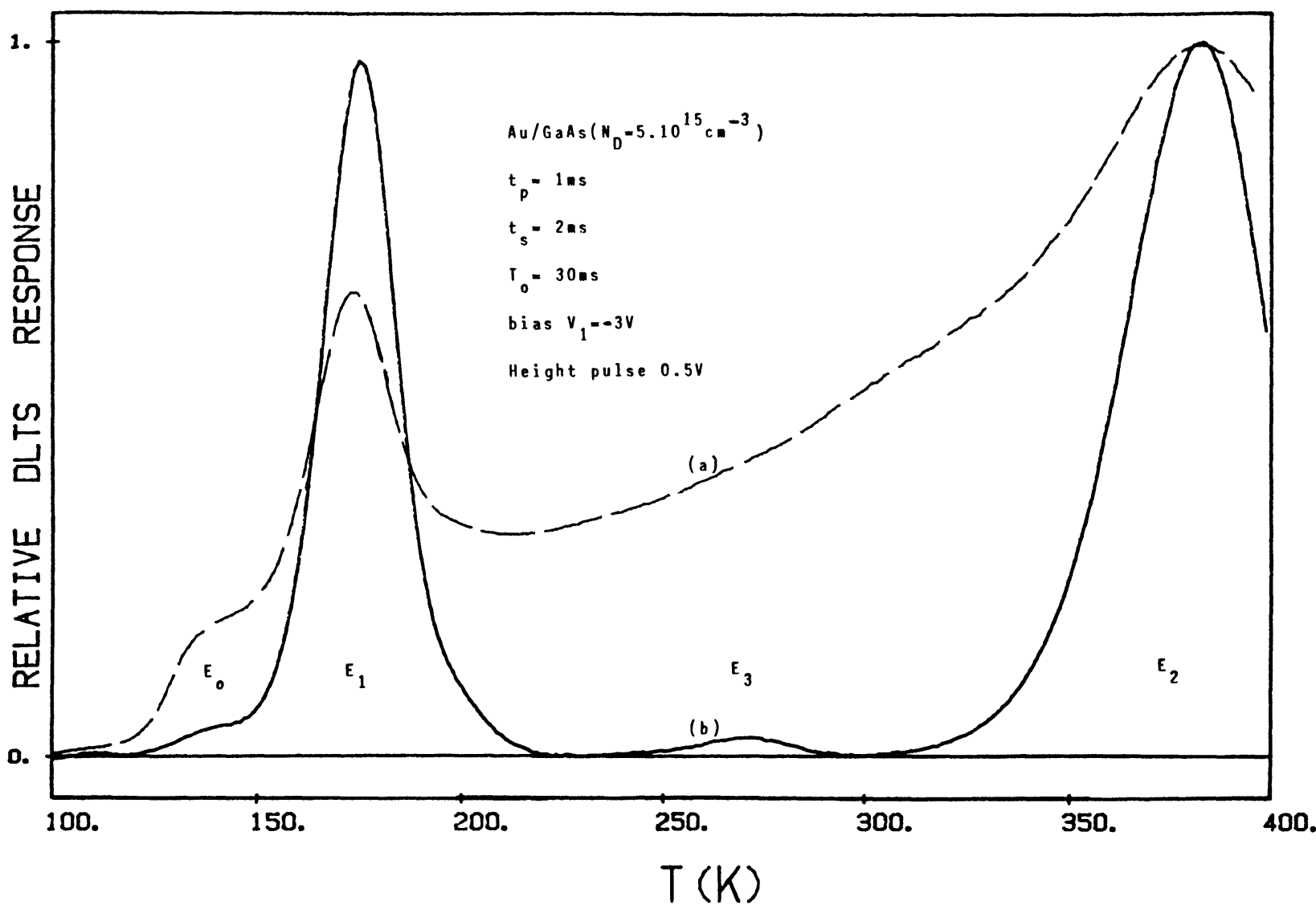

Fig. 3. - Normalized DLTS spectra of a GaAs Schottky diode, ((a) curve : capacitance meter used in the differential mode, (b) curve : method proposed here).

observed peaks. The duration of the pulse $t_{\mathrm{p}}$ and the aperture time $t_{\mathrm{s}}$ of the analogic switch $\mathrm{A} 1$ are relatively long compared to the period $T_{0}$ and as a consequence the base line of the DLTS signal is changing with the temperature in the spectrum $\{a\}$ and the peaks are broadened. As expected the spectrum $\{b\}$ has a zero base line and this greatly simplifies the characterization of the DLTS peaks as we will see here after.

The method has also been tested to check the electric field dependence of the $E_{1}$ DLTS peak. It is well known that the time constant $\tau(T)$ which is governed by the Poole-Frenkel or the phonon-assisted tunnelling effect is sensitive to the electric field in the depletion layer. As a consequence the electron traps in the depletion layer will not experience the same time constant. This is particularly true with high height of the refilling pulse. This effect is more pronounced in highly doped semiconductors because the electric field is linear with the square root of the dopant concentration.

This effect has been observed in various semiconductors and different models have been proposed to explain this behavior [8-10]. Here we report experimental results in a weakly doped GaAs $\left(N_{\mathrm{D}}=\right.$ $5 \times 10^{15} \mathrm{~cm}^{-3}$ ) semiconductor where the effect is not easy to be observed. In figure 4 are reported DLTS spectrum for different heights of the refilling pulse, the curves are shifted to low temperature as the refilling pulse is increased, this demonstrates that the times constant are decreased as expected. Thus, the automatic substraction of the base line allows to observe various effects with a great accuracy.

From the chronogram in figure 2 , at a temperature $T$, the time dependence of the signal $S_{\mathrm{D}}$ at the input of the lock-in amplifier can be written over one period as :

$$
\begin{aligned}
S_{\mathrm{D}}(t, T) & =\Delta C \cdot\left\{\exp \left(-\left(t-t_{\mathrm{p}}\right) / \tau(T)\right)-\right. \\
& \left.-\exp \left(-\left(T_{0}-t_{\mathrm{p}}\right) / \tau(T)\right)\right\} \cdot u\left(t-t_{\mathrm{s}}\right)
\end{aligned}
$$

where the origin of the time has been taken from the low to high transition of the refilling pulse, $u\left(t-t_{\mathrm{s}}\right)$ is the classical Heaviside function. $\tau(T)$ is the time constant at the temperature $T$ : the inverse of the thermal emission rate $e_{\mathrm{n}} . \Delta C$ is the magnitude of the capacitance transient decay, it is a function of the height of the pulse and it will be assumed, as usualy, independent of temperature.

The signal analysed by the lock-in amplifier corresponds to the first harmonic of the $S_{\mathrm{D}}$ Fourier series and it takes the following form : 


$$
S_{\mathrm{D} 1}(t, T)=a_{1}\left(\tau(T), t_{\mathrm{s}}, t_{\mathrm{p}}, T_{0}\right) \cdot \cos \omega t+b_{1}\left(\tau(T), t_{\mathrm{s}}, t_{\mathrm{p}}, T_{0}\right) \cdot \sin \omega t \quad \text { with } \quad \omega=2 \pi / T_{0}
$$

$a_{1}$ and $b_{1}$ have the following expressions :

$a_{1}=K\left[\left(-\tau \cdot \exp \left(-T_{0} / \tau\right)-\left(-\tau \cdot \cos \omega B+\omega \tau^{2} \sin \omega B\right) \times\right.\right.$

$$
\left.\times \exp (-B / \tau)) / D+((\sin \omega B) / \omega) \exp \left(-T_{0} / \tau\right)\right]
$$

$b_{1}=K\left[\left(\left(\omega \tau^{2} \exp \left(-T_{0} / \tau\right)+\left(\omega \tau^{2} \cos \omega B+\tau \cdot \sin \omega B\right) \exp (-B / \tau)\right) / D\right)+\right.$

$$
\left.+((1-\cos \omega B) / \omega) \exp \left(-T_{0} / \tau\right)\right]
$$

with

$$
D=\left(1+\omega \tau^{2}\right) \quad \text { et } K=\left(2 \Delta C / T_{0}\right) \exp \left(t_{\mathrm{s}} / \tau\right)
$$

At a temperature $T$, the DLTS signal at the output of the lock-in amplifier is then :

$$
S_{\mathrm{DLTS}}(T)=\left(1 / T_{0}\right)\left[\int_{t_{\mathrm{s}}}^{T_{0} / 2} S_{\mathrm{D} 1}(t, T) \mathrm{d} t-\int_{T_{0} / 2}^{T_{0}} S_{\mathrm{D} 1}(t, T) \mathrm{d} t\right]
$$

and it takes the form :

$$
S_{\mathrm{DLTS}}(T)=\left(1 / T_{0}\right)\left[-\left(a_{1} / \omega\right) \sin \omega t_{\mathrm{s}}+\left(b_{1} / \omega\right)\left(3+\cos \omega t_{\mathrm{s}}\right)\right]=\Delta C \cdot g\left(\tau(T), t_{\mathrm{s}}, t_{\mathrm{p}}, T_{0}\right) .
$$

Then, the parameters of a deep level, i.e. its apparent capture cross section $\sigma_{\infty}$ and its activation energy $\left(E_{\mathrm{a}}+E_{\sigma}\right)$ which verify the classical relation

$$
\tau^{-1}=A \sigma_{\infty} T^{2} \exp \left[-\left(E_{\mathrm{a}}+E_{\sigma}\right) / k T\right]
$$

are obtained by mean of a fit with the experimental curve. $E_{\mathrm{a}}$ and $E_{\sigma}$ are respectively the ionisation energy and the activation energy of the capture cross section of the deep level. A single scanning temperature was used in our experiments. The magnitude of

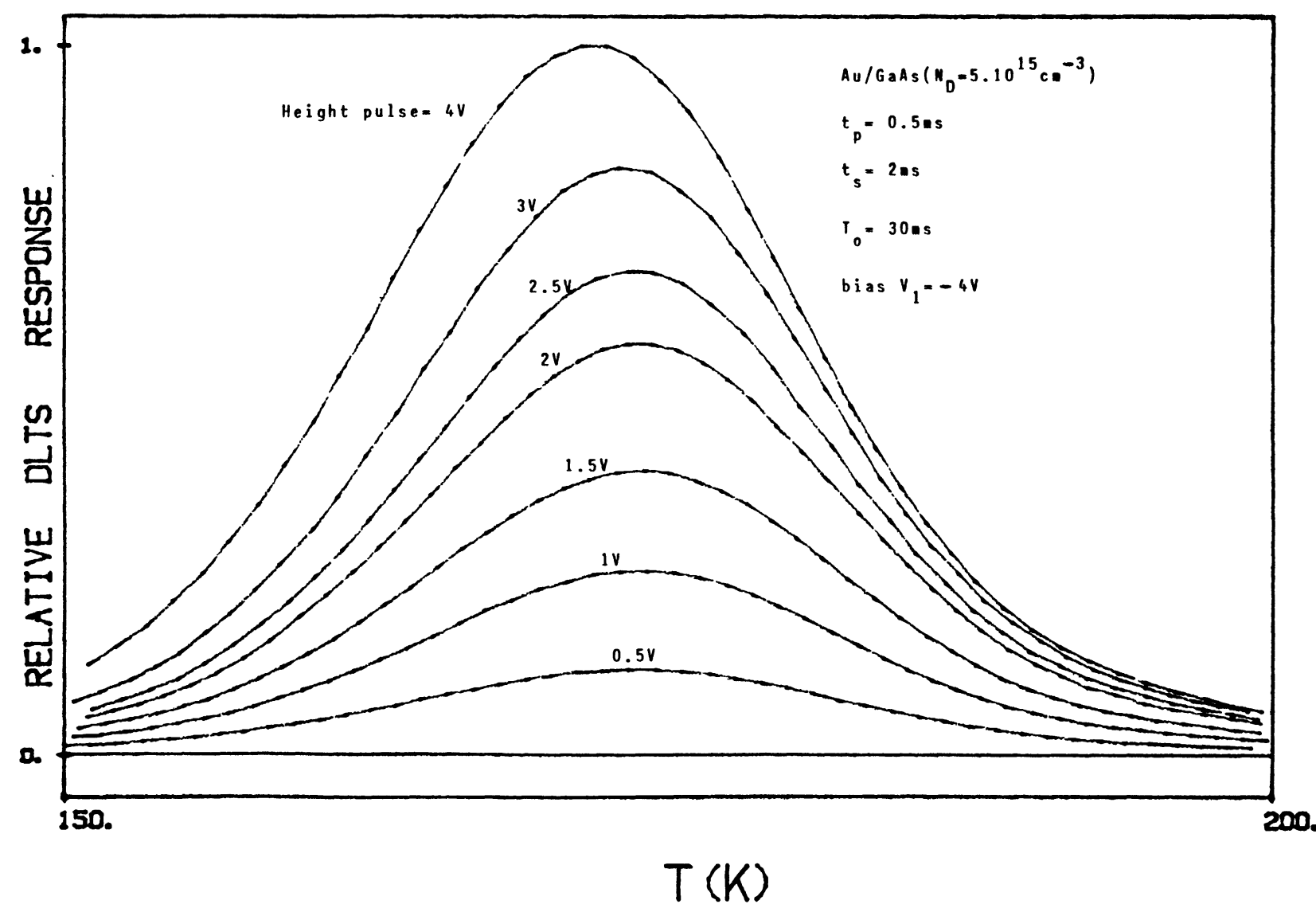

Fig. 4. - DLTS spectra for various heights of the refilling pulse, the shift to low temperature is due to the electric field dependence of the emission rate. 
the recorded signal at the temperature $T$ is $S_{\text {MDLTS }}(T)$ and the time constant $\tau(T)$ at any value of the temperature $T$ is now obtained by equalling the two ratios; i.e. $g(\ldots) / g(\ldots)_{\max }$ and $S_{\text {MDLTS }} / S_{\text {MDLTS max }}$ where $g(\ldots)_{\max }$ and $S_{\text {MDLTS max }}$ are the theoretical and experimental maximum, by using this method, the apparatus function is thus eliminated. This method is similar to those proposed by Le Bloa et al. [11].

The temperature dependence of the time constant $\tau(T)$ is calculated by a program. Firstly, due to the fact that the data acquisition is made with a one degree step in temperature, the temperature $T_{\mathrm{M}}$ of the maximum of the experimental curve is found by means of the derivation of a polynomial function fitting the five different experimental values around the maximum. The time constant $\tau(T)$ over the temperature range of interest is now obtained in two steps. Firstly, $\tau(T)$ is calculated from $T_{\mathrm{M}}$ to the lowest temperature, and then from $T_{\mathrm{M}}$ to the highest temperature. Each step uses a Newton method which is more rapidly convergent than a dichotomic method [12]. The $\log \left(e_{\mathrm{n}} / T^{2}\right)$ plots as a function of the inverse of the temperature for the two main peaks $E_{1}$ and $E_{2}$, which are shown in the inserts in figures 5 and 6 . From these plots activation energies of $0.31 \mathrm{eV}$ and $0.71 \mathrm{eV}$ and apparent capture cross sections of $2.9 \times 10^{-14} \mathrm{~cm}^{2}$ and $1.7 \times 10^{-14} \mathrm{~cm}^{2}$ are deduced for the $E_{1}$ and $E_{2}$ peaks respectively.

Normalized theoretical spectra of the $E_{1}$ and $E_{2}$ peaks have been calculated by using the equation (5) and the experimental values shown above for $\sigma_{\infty}$ and $\left(E_{\mathrm{a}}+E_{\sigma}\right)$. They are plotted in figures 5 and 6. A good agreement with experimental curves is obtained. However the high temperature foot side of the calculated $E_{1}$ peak decreases more rapidly than the experimental one. This effect does not occur with the $E_{2}$ peak. In this temperature range the calculated time constant of the $E_{1}$ peak is greater than the time response of the capacitance meter (for instance $\tau(190 \mathrm{~K})=2 \mathrm{~ms} \gg 180 \mu \mathrm{s})$, so we cannot invoke some instrumentation troubles; up to now this behaviour has not been well understood.

The results presented here demonstrate that the method is very efficient to characterize quickly the parameters of the deep levels and in our case the majority carriers traps can be well described with a single time constant.

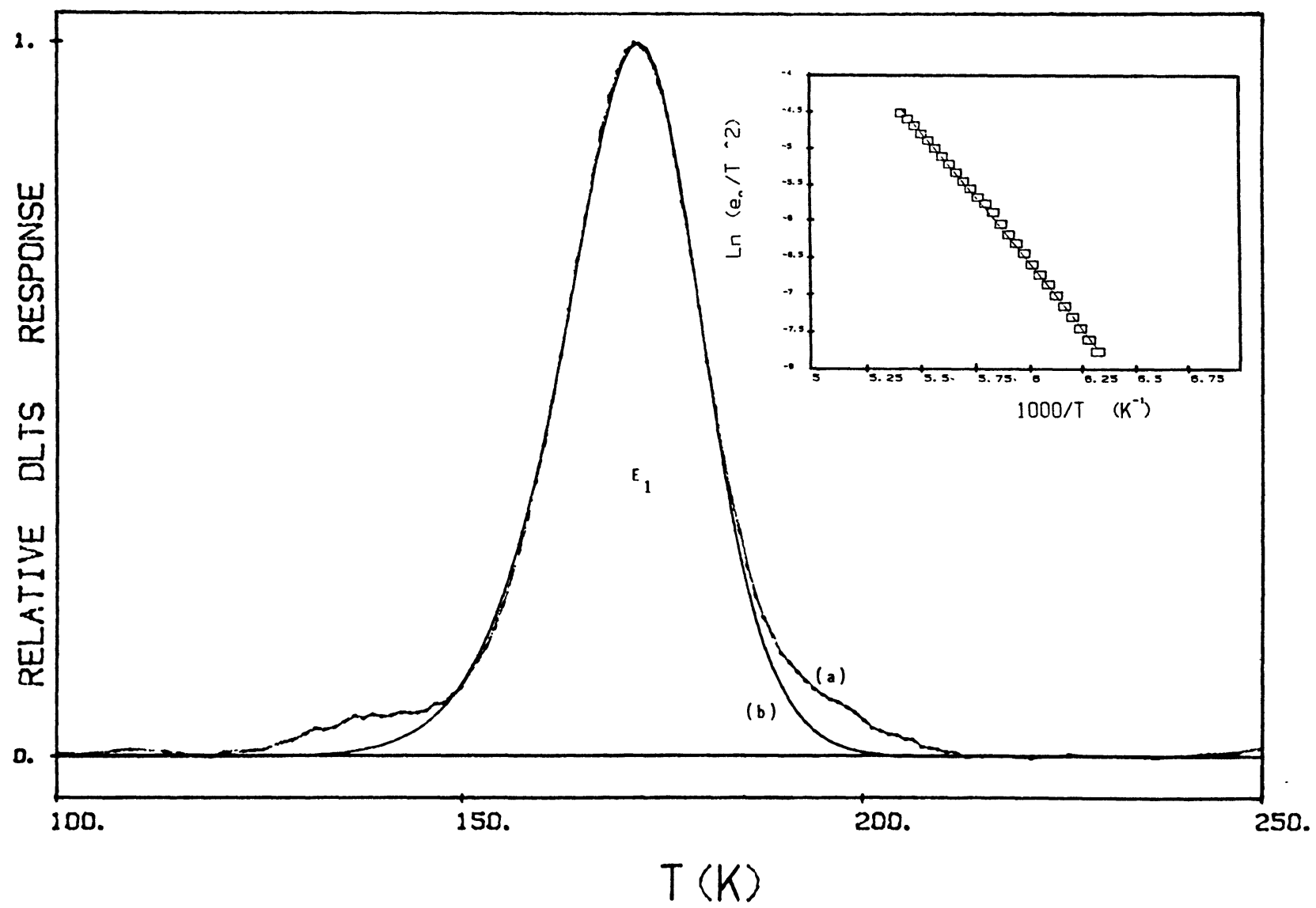

Fig. 5. - (a) experimental and (b) calculated DLTS spectra of the $\mathrm{E}_{1}$ peak. The insert shows the $\operatorname{Ln}\left(e_{\mathrm{n}} T^{-2}\right)$ plot versus the inverse temperature. 


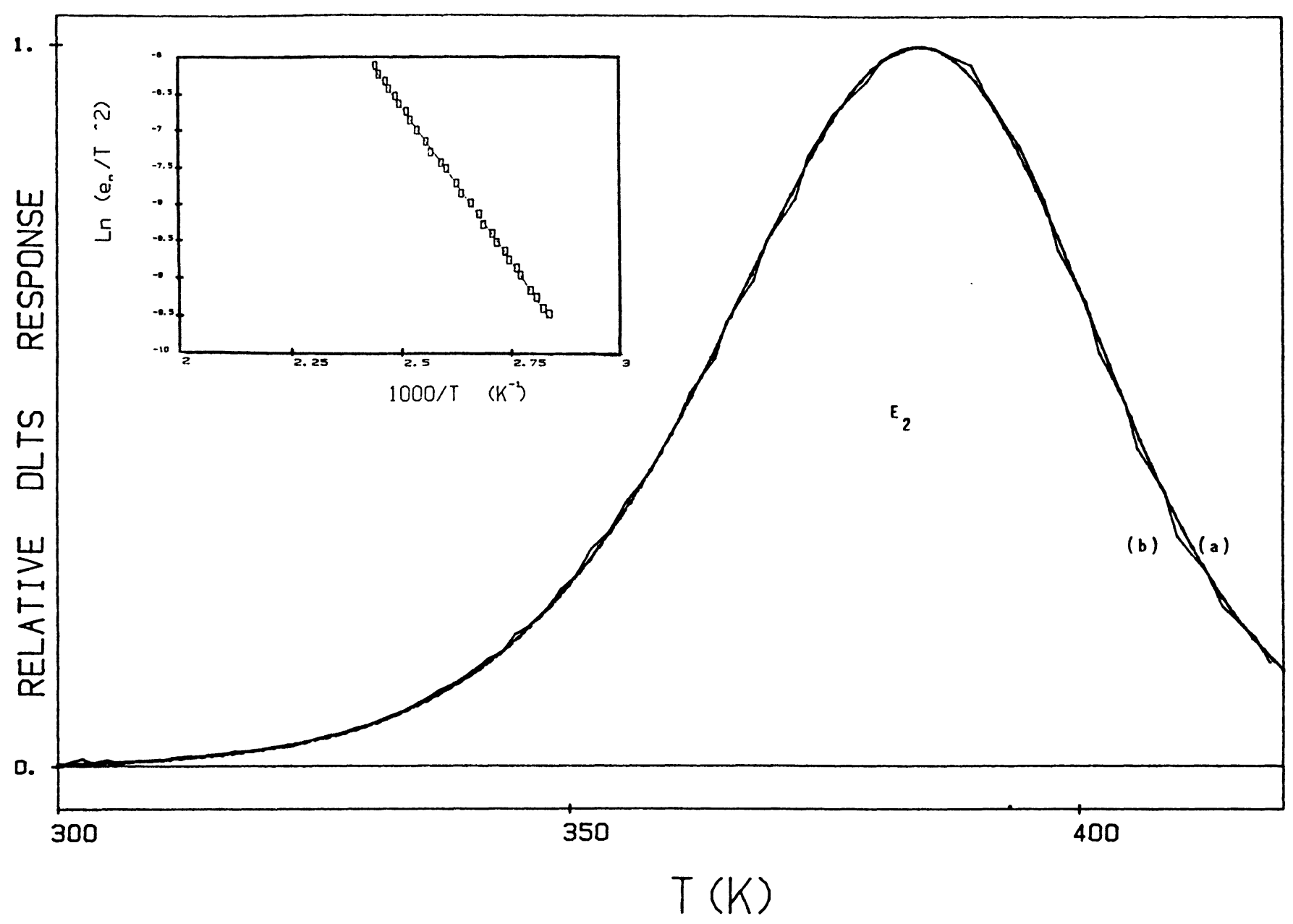

Fig. 6. - (a) experimental and (b) calculated DLTS spectra of the $\mathrm{E}_{2}$ peak. The insert shows the $\operatorname{Ln}\left(e_{\mathrm{n}} T^{-2}\right)$ plot versus the inverse temperature.

\section{Conclusion.}

This paper describe a method to suppress the base line problem in the lock-in DLTS technique. The method has been tested very sucessfully with of a GaAs Scottky diode and the electric field dependence has been observed in a weakly doped semiconductor, $N_{\mathrm{D}}=5 \times 10^{15} \mathrm{~cm}^{-3}$. The aim of the method is based on the use of a sampler holder and a substractor and it can be easily implanted in an existent set-up. Programs and more details about the instrumentation can be provided on request.

\section{Acknowledgements.}

We thank. H. Ricard and A. Chaouki for many help full discussions and the Centre National d'Etudes des Télécommunications (C.N.E.T. Lannion 2) for providing the GaAs diodes.

\section{References}

[1] Lang D. V., J. Appl. Phys. 45 (1974) 3023.

[2] Shulz M. and Johnson N. M., Appl. Phys. Lett. 31 (1977) 622.

[3] Shulz M. and Johnson N. M., Solid State Commun. 25 (1978) 481.

[4] LANG D. V., Thermally Stimulated Relaxation in Solids, Ed. P. Braünlich (Springer Verlag) 1979, p. 93-133.

[5] Pons D., Mooney P. M. and Bourgoin J. C., J. Appl. Phys. 51 (1980) 2038.
[6] Tokuda Y. and Shimizu N., Jpn J. Appl. Phys. 18 (1979) 309.

[7] LE BLOA A., private communication.

[8] Korol E. N., Sov. Phys. Solid. State 19 (1977) 1327.

[9] Vincent G., Thèse Lyon (1978).

[10] Pons D., Thèse Paris VI (1979).

[11] Le BoA A., Favennec P. N. and Colin Y., Physica Status Solidi (a) 64 (1981) 85.

[12] SibONY M. et MARDON J. Cl., Systèmes linéaires et non linéaires, Analyse numérique 1, Herman Ed. (1984). 